\title{
Notes On Economic Plants
}

The Role of Barley among the Shuhi in the Tibetan Cultural Area of the Eastern Himalayas.-Barley (Hordeum vulgare L.) derives from the wild species Hordeum spontaneum K. Koch and was one of the earliest domesticated grains. Like many other domesticated plants, it originated in the Near East, where it was first cultivated around 6000 B.C. Barley spread out from Mesopotamia, along the coast of North Africa, up the Nile to Eritrea and Ethiopia, into Europe where it reached Spain in about 5000 B.C., then eastward to India, and reaching China in the late second millennium B.C. $(1,2,3)$. Because of barley's adaptability to rough climates and its short vegetation period, it can be cultivated near the Arctic Circle as well as on the Tibetan plateau at altitudes of over 3,500 meters (m), where other crops are difficult to grow ( $l$, $4,5,6,7)$. The wide geographical distribution of barley, its local adaptation to different habitats, and its diverse uses in different communities have led to a great number of varieties. Barley is differentiated by the two-rowed type and the six-rowed type as well as the naked and hulled varieties. In Tibet, almost all cultivated varieties are naked six-rowed barley, which is well adapted to the harsh environment and can be processed easily $(3,6,8)$. Barley is the main crop of Tibetan agriculture; in the form of tsampa, i.e., flour prepared from roasted grains, it is a staple food of the area. Furthermore, it plays a manifold role in cultural and religious activities. Its cultural importance also is reflected in its use as a unit of measure in Tibetan iconography, where eight barley grains are equal to a "finger-width" or "small-measure" (9).

Based on observations during eight months of fieldwork in 1996, 2004, and 2005, this paper's focus is on the cultivation, processing, and ritual uses of barley among the Shuhi in the eastern Himalayas, and their reflection of the strong Tibetan influences in the area. The Shuhi are a Tibeto-Burman ethnic group of around 1,500 people living exclusively in the subtropical area near the bottom of the Shuiluo valley $(2,000-$ $2,400 \mathrm{~m}$ ) of southwest Sichuan (China). They speak their own Tibeto-Burman language and although the kinship with other ethnic groups is unclear, they are officially counted among the Tibetans (Chin.: zangzu).

Crop Cultivation. The Shuhi practice subsistence agriculture with crop rotations, cultivating barley (Shuhi: maze) and wheat (ze) during the winter, and wet rice (shue) and corn (kashe) during summer. They use terraced fields irrigated with multiple irrigation channels. To keep the fields fertile, they spread organic fertilizer twice a year. The fertilizer consists of manure mixed with oak leaves (preferentially Quercus guajavifolia $\mathrm{H}$. Lév.). During the Tibetan New Year (December 8th, agricultural calendar), they place a bunch of plants (called telasyi) in the middle of the barley and wheat fields to ask the gods for good growth and large yields. A telasyi is made of Cornus oblonga Wall. (xiuga), Pistacia weinmannifolia Poiss. ex Franch. (igi), Pinus yunnanensis Franch. (thoru) and Phyllostachys sp. (tlahu). A similar ceremony is conducted in March for the rice seedlings. At that time, Clematis spp. (ginier) and other flowers are added to the bunch, as rice is believed to be fond of flowers. For corn, no such ritual exists. The rice cultivation distinguishes the Shuhi from neighboring ethnic groups, such as the Pumi and Gami-Tibetans. This distinction is reflected even in their name Shuhi, which can be translated as "rice people."

Table 1 summarizes the local names of the crop varieties, the size of cultivated areas, and yields. While the traditional wheat varieties were replaced 20 years ago, the two main local barley varieties, a blackish (mazeni) and a whitish one (mazeho), both of which belong to the naked six-rowed type, have been cultivated and exchanged between households since ancient times. Barley and wheat take up about the same field area, but wheat yields are considerably larger per cultivated acreage. Interestingly, drying, threshing, and winnowing of the harvested crop take place on the flat roofs of the houses (Fig. 1A and 1B).

Processing of Barley. Like in other Tibetan areas, barley is processed into tsampa (hui), barley wine (xie), and spirit (aji). Before each meal, 
butter tea (jue), which is served in maple cups, is consumed with tsampa, which is stored in turned maple pots (buru). In contrast to other Tibetan areas where tsampa usually is mixed with butter tea and formed into little balls before consumption, the Shuhi typically throw tsampa into their mouth with a spoon and swallow it with butter tea or barley wine. To produce tsampa, barley or occasionally wheat and corn, is cooked with water and then roasted over the fire in a big iron pan. Next the grains are milled with a vertical waterwheel mill (raxi; Fig. 2), which is in a small stone hut built adjacent to streams in side valleys. A few houses in the area run a mill together. Similar mills are described for other Tibetan areas $(10)$.

Barley wine and spirits are of major importance among the Shuhi. They are used for serving guests and as gifts. The "black" barley variety is the preferred variety for producing beverages, although the final taste of the beverage depends not only on the variety but also on the roasting conditions (Fig. 1C). To make barley wine, the grain is roasted. After roasting, water is added and the barley grains are cooked until all water is absorbed. Three to four mortared "chu" (white rings containing fish liver, honey, and other ingredients) are added to facilitate the fermentation process. The fermenting barley rests at least one night and then is poured into earthen pots, which are tightly sealed with ash and clay. Barley wine can be extracted as early as three days after the pots are sealed but the pots also can be stored for several months. For extraction, the concentrated barley wine is diluted with water (Fig. 1D). This process can be repeated two or three times, and the remaining fermented grains then can be distilled for spirits. Finally, the grains are fed to the cattle. When a new pot is opened, incense is burned, a conchshell trumpet (hliesi) is blown, and the new wine is first offered to the gods.

Role of Barley in Rituals and Festivals. Both tsampa and barley wine play an important role as food offerings and libation. Every morning the Shuhi worship the gods by burning incense on the flat roofs of their houses. A spoon of tsampa mixed with marigold (Tagetes erecta $\mathrm{L}$.; deng buhu) and one sip of barley wine or milk is poured over the incense offering as food for the gods. On special days, walnuts (Juglans regia L.; kara) are added (11). 

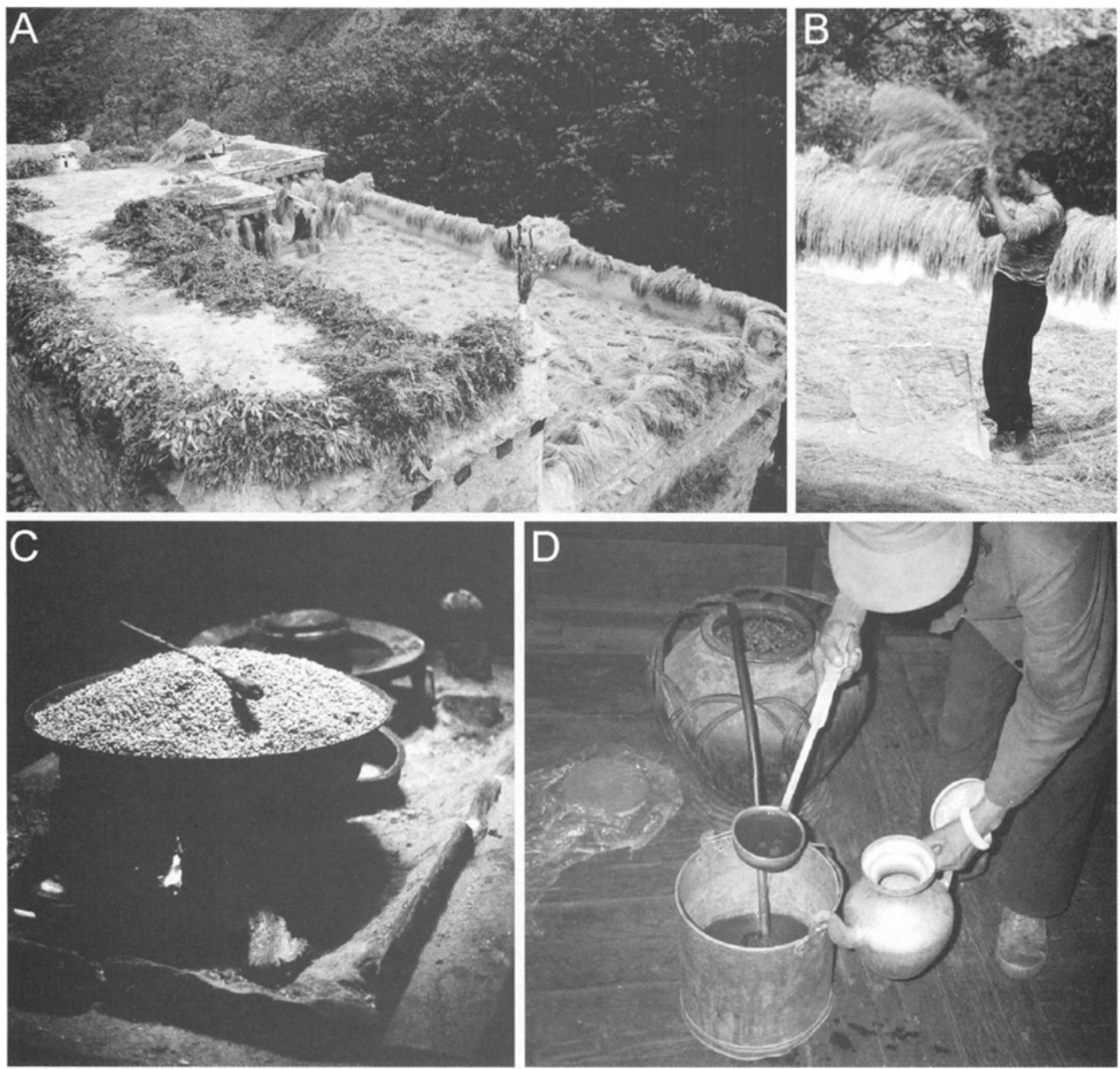

Fig. 1A. Drying the crops on the flat roof. Fig. 1B. For threshing, dried crop bundles are struck against a big vertical stone located in the middle of the roof. Fig. 1C. For producing barley wine, the grains are roasted in a big iron pan over the fire first. Fig. 1D. Extraction of barley wine.

Two harvest festivals are celebrated each year, accompanied by a complex exchange of food between the households. The beginning of the barley harvest, called hasheng ("new crop"), is celebrated on the first and second days of May. A bottle of old barley wine has to be finished before the new wine from the current year's harvest can be served. Old tsampa is replaced with new. The house and house altar are decorated with walnut leaves and different flowers including marigold and pomegranate (Punica granatum L.; sami). New wine and new tsampa mixed with marigold flowers are burnt in the hearth as an offering to the gods, thanking them for the harvest and asking them for large crops in the future.

Dough figures (jaba) prepared from tsampa are important components of local rituals. Among the Shuhi, both the dumbu priests, i.e., local ritualists, and Buddhist monks form figures from newly milled barley tsampa for different religious or healing activities. The figures are used as effigies of important gods (e.g., mountain, water, and house gods) as well as effigies of demons, ancestors, family members, or animals. On some figures wooden molding boards with engraved symbols, e.g., animals, humans or deities, are impressed. The figures also might be 


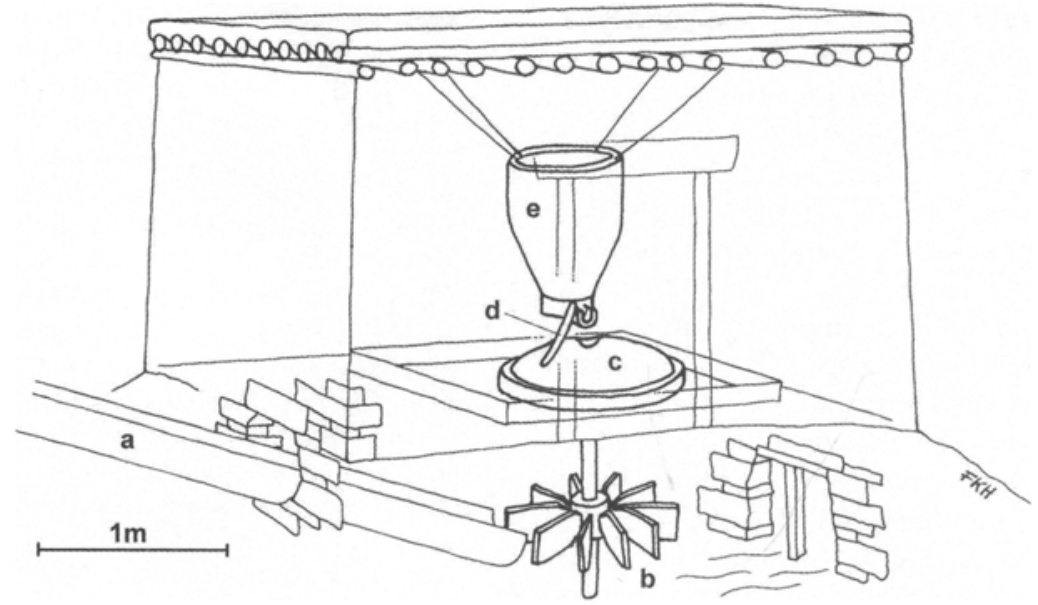

Fig. 2. A water mill used by the Shuhi for producing tsampa. Drawing by Franz K. Huber. Fig. 2a. Wooden water channel. Fig. 2b. Multiple-winged waterwheel. Fig. 2c. Upper, moving mill stone. Fig. 2d. The wooden stick is transferring vibrations from the millstone to the grain feeder, which causes the grain to fall evenly into the mill. Fig. 2e. Grain feeder.

colored and decorated with butter (Fig. 3). They are used to represent the places of the gods or might be offered at the places of the spirits. They can be burned or thrown away while driving the demons off, they might be offered to the demons as a substitute for a sick person, or they might be eaten by the participants of the ritual as a medicinal or spiritual substance (Fig. 4).

The ritual use of tsampa dough figures (Tibet: gtorma) is distributed widely in the Tibetan cultural area, and is documented for the dongba priests of the Naxi and the ddaba priests of the Mosuo $(12,13)$. It is thought to have descended from ancient Bon traditions, the ancient animistic religion preceding Buddhism in Tibet, and

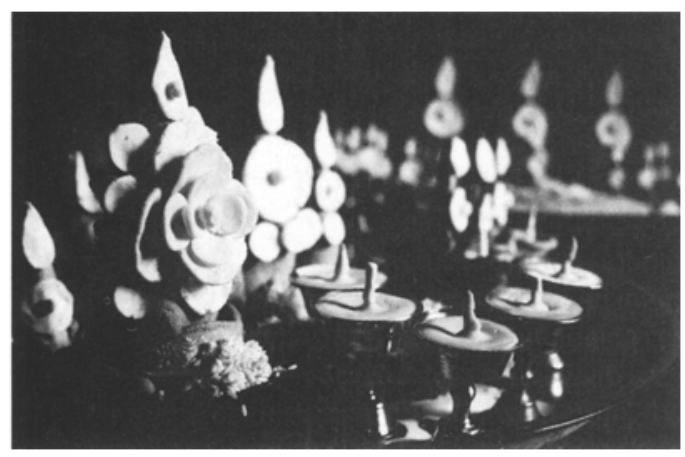

Fig. 3. Dough figures (Shuhi: jaba) that have been prepared from tsampa and then decorated with butter. often is considered a substitute for animal sacrifice $(9,14)$.

Conclusion. In Tibet, barley is the main staple food and plays assorted roles in cultural and religious activities. Interestingly, the Shuhi call themselves "rice people," indicating that rice cultivation is a central part of their cultural identity. This might point to some relations with other rice cultivating groups further south, such as the Naxi. However, rice plays only a minor role in religious and ritual activities compared with

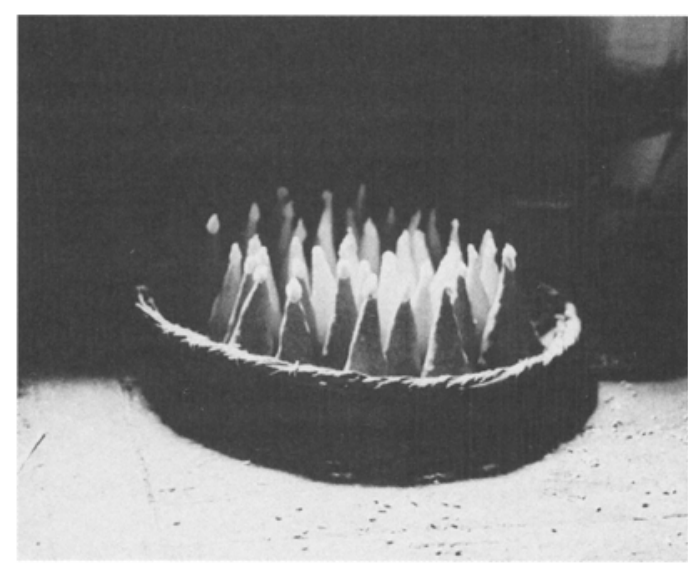

Fig. 4. Dough figures for consumption by the participants of a ritual. 
barley. This observation demonstrates the strong influence of Tibetan Buddhism in the area. Such influence on Tibeto-Burman ethnic groups in west Sichuan also has been shown in linguistic studies. For example, Sun (15) stresses that, in the Tibeto-Burman languages of western Sichuan, religious terms frequently are borrowed from the Tibetan language.

Barley is not only an important ritual plant among the Shuhi, but it also is a main food staple that is consumed as tsampa and barley wine. This dual usage and the equal importance of both aspects is supported by results from grouping analyses (unpublished data), which reveal that barley is in the group of "edible plants" as much as it is in the group of "plants that are sent to the gods." For the Shuhi, the importance of rice as a main staple food and of barley as both a staple food and a component of daily rituals reflects their position between the two dominant ethnic groups in the region: the Naxi in the south and the Tibetans in the north.

Acknowledgments. We would like to thank all the inhabitants of Shuiluo for their hospitality and support, Gao Fu, Chen Yulin, and Li Ting for their help in many aspects of the fieldwork, and Philip Blumenshine for critical comments on the manuscript. This project has been funded by the Swiss National Science Foundation PBZHA-104354.

Literature Cited: (l) Harlan, J. R. 1976. Barley. Pages 93-98 in N. W. Simmonds, ed., Evolution of crop plants. Longman, London. (2) Briggs, D. E. 1978. The origin of cultivated barley. Pages $81-88$ in D. E. Briggs, ed., Barley. Chapman and Hall, London. (3) Müller, K.-J. 2003. About hulless food barley, tsampa, giotta and gofio, http://www. speisegerste.de/ (23.12.2004). (4) Shands, H. L. and A. D. Dickson. 1953. Barley-Botany, production, harvesting, processing, utilization, and economics. Economic Botany 7:3-26. (5) Nakao, S. 1956. Barley. Pages 313-343 in H. Kihara, ed., Land and crops of Nepal Himalaya, Vol. 2. Japan Society for the Promotion of Science, Tokyo. (6) Staudt, G. 1961. The origin of cultivated barleys: A discussion. Economic Botany 15:205-212. (7) Franke, W. 1997. Nutzpflanzenkunde. Georg Thieme Verlag, Stuttgart, pp. 88-90. (8) Tsuyuzaki, H., $\mathrm{K}$. Takeda, and T. Komazaki. 2000. Barley varieties and its cultivation in east part of Tibet plateau. Japanese Journal of Crop Science 69:345-350 (English abstract). (9) Beer, R. 1999. Encyclopedia of Tibetan symbols and motifs. Shambhala Publica- tions, Boston, pp. 321-325. (10) Nakao, S. 1956. Agricultural Practice. Pages 95-107 in H. Kihara, ed., Land and crops of Nepal Himalaya, Vol. 2. Japan Society for the Promotion of Science, Tokyo. (II) Weckerle, C. S., F. K. Huber, Y. P. Yang, and W. B. Sun. 2005. Walnuts among the Shuhi in Shuiluo, eastern Himalayas. Economic Botany 59(3):287-290. (12) He, L. M. and S. C. He. 1998. The Dtô-mbà ceremony to propitiate the demons of suicide. Pages $239-272$ in M. Oppitz and E. Hsu, eds., Naxi and Moso ethnography: Kin rites and pictographs. Völkerkundemuseum der Universität Zürich, Zürich. (13) Mathieu, C. 1998. The Moso ddaba religious specialists. Pages 209-234 in M. Oppitz and E. Hsu, eds., Naxi and Moso ethnography: Kin rites and pictographs. Völkerkundemuseum der Universität Zürich, Zürich. (14) Snellgrove, D. 1967. The nine ways of Bon. Oxford University Press, London, p. 14. (15) Sun, H. K. 1990. Languages of the ethnic corridor in western Sichuan. Translated by Jackson T.-S. Sun. Linguistics of the Tibeto-Burman Area 13.1:1-31.

- Caroline S. Weckerle (Kunming Institute of Botany, Chinese Academy of Sciences and Institute of Systematic Botany, University of Zurich, Kunming Institute of Botany, Heilongtan, 650204 Kunming, China; e-mail weckerle@ ethnobot.ch), Franz K. Huber, Yang Yongping, and Sun Weibang (Kunming Institute of Botany, Chinese Academy of Sciences, Heilongtan, 650204 Kunming, China).

The cultural and ecological roles of Mimosa species in the Tehuacán-Cuicatlán Valley, Mexico.-Mexican deserts, which possess a high plant and animal diversity, are considered the center of origin and evolution of many taxa $(1,2)$. Since pre-Columbian times they have supported the livelihoods of different local communities (3). The Tehuacán-Cuicatlán Valley, part of which was declared a Biosphere Reserve in 1998, is in a semiarid region of the southcentral states of Puebla and Oaxaca, Mexico $\left(17^{\circ} 20^{\prime}-18^{\circ} 53^{\prime} \mathrm{N}\right.$, and $\left.96^{\circ} 55^{\prime}-97^{\circ} 44^{\prime} \mathrm{W}\right)$. It has a surface area of ca. 10,000 square kilometers $\left(\mathrm{km}^{2}\right)$. The high level of plant diversity includes ca. 3,000 species, of which 30 percent are estimated to be endemic $(4,5,6)$. The Fabaceae family comprises 10 percent of the plant species of the zone and 72 legume genera (288 species) have been reported $(6)$. Of the 15 legume spe- 